\title{
Dowco-214 の主要衛生害虫に対する殺虫効果
}

I．室内試験によるゴキブリに対する殺虫効力評価

\author{
北坦忠温* 中山 勇* 杉山繁雄* \\ 坂 本 塀** \\ *クミアイ化学工業株式会社生物科学研究所（静岡県小笠郡菊川町加茂 3,360 ) \\ ** クミアイ化学工業株式会社化学研究所（静岡県清水市渋川100）
}

（受領：1972年11月20日）

Effectiveness of Dowco-214 on some insects of public health importance

I. Laboratory evaluation tests for cockroaches

\author{
Tadaharu KitagAKI,* Isamu NAKAyAma,* Shigeo Sugryama* \\ and Akira SAKAMOTO** \\ * Life Science Research Institute, Kumiai Chemical Ind. Co., Ltd., Kikukawa, Shizuoka \\ ** Chemical Research Institute, Kumiai Chemical Ind. Co., Ltd., Shimizu, Shizuoka
}

\section{まえがき}

Dow Chemical 社が開発した, 新有機燐殺虫剂 Dowco-214 の殺虫効力についてはすでに多くの報告がなさ れている (Kenaga et al., 1965 ; Kenaga, 1971 ; 中山 ら, 1971 ; Nakayama et al., 1972 ; Rigterink et al., 1966 ; Kitagaki et al., 1972)。 また，温血動物に対す る毒性は，井上ら（1971）がマウスの急性経口毒性は $3,800 \mathrm{mg} / \mathrm{kg}$ と報告し，非常に低毒性である。

䈉者らは，温血動物に対する毒性面から推察してDowco-214 は防疫用として好ましい殺虫鼡のひとつと考 え，ゴキブリ類に対する殺虫効力を市販の数種防疫用殺 虫剂と比較検討し， $2 ， 3$ の知見を得たので報告する.

本文に入るに際し，有益なご助言とご指導を賜った名 古屋大学農学部斉藤哲夫教授, 当研究所長石井義男博士, ならびに原稿のご校閲をいただいた当研究所主任研究員 長沢純夫博士に拉礼申し上げる. また当研究所浅野昌 司, 楖原啓高, 伊藤さな总の諸氏の熱心な助力に謝意を 表する。

\section{試験材料}

1）供試昆虫

供詰したチャバネゴキブリ（Blattella germanica）,
ワモンゴキブリ(Periplaneta americana)，拉よびクロ ゴキブリ(Periplaneta fuliginosa) は静岡県清水市で採 集し，クミアイ化学工業株式会社生物科学研究所で1960 年より実験動物用固型飼料（オリエンタル酵母株式会社 製品）と水を与え，温度 $25 \pm 1{ }^{\circ}$ C，湿度 R.H. $60 \pm 5 \%$ の環境条件下で累代飼育した采統である。

2) 供試薬鼡

供試した 殺虫剤はカラムクロマトグラフィーで精製 し，薄層クロマトグラフィーで不純物を含まない純品で あることを確認して用いた。 それぞれの化学名はつぎの とおりである。

1) Dowco-214: $O, O$-dimethyl $O$ - (3,5,6-trichloro2-pyridyl) phosphorothioate

2) Dursban ${ }^{\circledR}: O, O$-diethyl $O$ - (3, 5,6-trichloro2-pyridyl) phosphorothioate

3) Fenitrothion: $O, O$-dimethyl $O$-(3-methyl-4nitrophenyl) phosphorothioate

4) Diazinon: $O, O$-diethyl $O$-(2-isopropyl-6-methyl-4-pyrimidinyl) phosphorothioate

5) Fenthion : $O, O$-dimethyl $O$ - (3-methyl-4-mercaptophenyl) phosphorothioate

6) Dichlorvos: $O, O$-dimethyl 2,2,2-chlorovinyl phosphonate 
7) Trichlorfon: $O, O$-dimethyl 1-hydroxy-2,2,2trichloroethyl phosphonate

8) Malathion : $O, O$-dimethyl $S$-(1,2-dicarboethoxy) ethyl phosphorothioate

9) Dieldrin : 1,2,3,4,10,10-Hexachloro-6,7-epoxy1, 4, 4 a, 5, 6, 7, 8, 8a-octahydro-1, 4-endo, exo-5, 8-dimethanonaphthalene

\section{試験方法}

1. 微量滴下法
所定の濃度に稀䐆した各供試薬阂のアセトン溶液 $1 \mu \mathrm{l}$ を，炭酸ガスで麻酔したゴキブリ成虫の腹面中脚間にマ イクロシリンジで榈下施用した，処理した個体は 10 頭を 1 群として, 直径 $9 \mathrm{~cm}$, 高さ $7 \mathrm{~cm}$ のガラス容器に入 れ，網ぶたをし，餌を与えて飼青と同じ環境条件下に拉 き，24時間後これらの生死を観察した。

\section{2. 限定時間接触法による残效性}

$10 \times 10 \mathrm{~cm}$ の合板执よびガラス板に所定濃度のアセト ン薬液 $1 \mathrm{ml}$ を均一に滴下し, 風乾後, 直径 $9 \mathrm{~cm}$, 高さ $3 \mathrm{~cm}$ のガラスリングを置き，その中にチャバネゴキブ

Table 1 Insecticidal activity of several household insecticides to male adults of cockroaches evaluated by topical application

\begin{tabular}{|c|c|c|c|c|c|c|}
\hline \multirow{2}{*}{ Cockroach } & \multirow{2}{*}{ Chemical } & \multirow{2}{*}{$\begin{array}{l}\text { Regression } \\
\text { equation }\end{array}$} & \multicolumn{2}{|c|}{$\mathrm{LD}_{50} *$} & \multicolumn{2}{|c|}{$\mathrm{LD}_{s 0}$} \\
\hline & & & $\mu \mathrm{g} / \hat{\beta}$ & $\mu \mathrm{g} / \mathrm{g}$ & $\mu \mathrm{g} / \hat{\delta}$ & $\mu \mathrm{g} / \mathrm{g}$ \\
\hline \multirow{8}{*}{ B. germanica** } & Dowco-214 & $y=7.608+4.275 x$ & $\begin{array}{c}0.245 \\
(0.208-0.285)\end{array}$ & $\begin{array}{c}4.297 \\
(3.648-4.999)\end{array}$ & 0.489 & 8.577 \\
\hline & Dursban & $y=6.977+5.429 x$ & $\begin{array}{c}0.432 \\
(0.377-0.499)\end{array}$ & $\begin{array}{c}7.577 \\
(6.613-8.752)\end{array}$ & 0.745 & 13.067 \\
\hline & Fenitrothion & $y=7.395+4.945 x$ & $\begin{array}{c}0.328 \\
(0.283-0.375)\end{array}$ & $\begin{array}{c}5.753 \\
(4.964-6.578)\end{array}$ & 0.595 & 10.436 \\
\hline & Diazinon & $y=6.443+4.423 x$ & $\begin{array}{c}0.472 \\
(0.345-0.657)\end{array}$ & $\begin{array}{c}8.279 \\
(6.051-11.524)\end{array}$ & 0.919 & 16.119 \\
\hline & Malathion & $y=5.606+3.193 x$ & $\begin{array}{c}0.646 \\
(0.452-1.181)\end{array}$ & $\begin{array}{c}11.331 \\
(7.928-20.715)\end{array}$ & 1.628 & 28.555 \\
\hline & Fenthion & $y=6.372+3.858 x$ & $\begin{array}{c}0.441 \\
(0.307-0.651)\end{array}$ & $\begin{array}{c}7.735 \\
(5.385-11.419)\end{array}$ & 0.995 & 17.452 \\
\hline & Dichlorvos & $y=7.527+3.178 x$ & $\begin{array}{c}0.160 \\
(0.113-0.202)\end{array}$ & $\begin{array}{c}2.806 \\
(1.982-3.543)\end{array}$ & 0.837 & 14.681 \\
\hline & Dieldrin & $y=6.178+4.338 x$ & $\begin{array}{c}0.535 \\
(0.397-0.758)\end{array}$ & $\begin{array}{c}9.384 \\
(6.963-13.295)\end{array}$ & 1.057 & 18.540 \\
\hline \multirow{6}{*}{$P$. americana*** } & Dowco-214 & $y=4.411+2.883 x$ & $\begin{array}{c}1.601 \\
(1.009-2.433)\end{array}$ & $\begin{array}{c}1.176 \\
(0.708-1.786)\end{array}$ & 4.457 & 3.272 \\
\hline & Dursban & $y=3.764+6.946 x$ & $\begin{array}{c}1.506 \\
(1.248-1.989)\end{array}$ & $\begin{array}{c}1.106 \\
(0.916-1.460)\end{array}$ & 2.304 & 1.691 \\
\hline & Fenitrothion & $y=4.250+2.214 x$ & $\begin{array}{c}2.182 \\
(1.297-4.606)\end{array}$ & $\begin{array}{c}1.602 \\
(0.925-3.382)\end{array}$ & 8.274 & 6.075 \\
\hline & Diazinon & $y=2.490+5.164 x$ & $\begin{array}{c}3.601 \\
(2.368-3.876)\end{array}$ & $\begin{array}{c}2.248 \\
(1.738-2.845)\end{array}$ & 5.423 & 3.981 \\
\hline & Fenthion & $y=3.079+2.273 x$ & $\begin{array}{c}7.005 \\
(4.491-19.798)\end{array}$ & $\begin{array}{c}5.143 \\
(3.297-14.536)\end{array}$ & 25.662 & 18.841 \\
\hline & Dichlorvos & $y=5.739+3.619 x$ & $\begin{array}{c}0.625 \\
(0.434-1.051) \\
\end{array}$ & $\begin{array}{c}0.459 \\
(0.319-0.771) \\
\end{array}$ & 1.413 & 1.037 \\
\hline \multirow{4}{*}{ P. fuliginosa**** } & Dowco-214 & $y=2.454+4.563 x$ & $\begin{array}{c}3.614 \\
(2.989-4.433)\end{array}$ & $\begin{array}{c}4.141 \\
(3.425-5.079)\end{array}$ & 6.900 & 7.906 \\
\hline & Dursban & $y=2.679+5.915 x$ & $\begin{array}{c}2.467 \\
(2.099-2.876)\end{array}$ & $\begin{array}{c}2.827 \\
(2.405-3.295)\end{array}$ & 4.065 & 4.657 \\
\hline & Fenitrothion & $y=3.177+4.079 x$ & $\begin{array}{c}2.799 \\
(2.178-3.618)\end{array}$ & $\begin{array}{c}3.207 \\
(2.495-4.154)\end{array}$ & 5.770 & 6.611 \\
\hline & Diazinon & $y=3.601+2.813 x$ & $\begin{array}{c}3.148 \\
(2.080-8.916)\end{array}$ & $\begin{array}{c}3.602 \\
(2.323-10.216)\end{array}$ & 8.974 & 10.282 \\
\hline
\end{tabular}

* Figures in parenthesis denote the fiducial limits at $95 \%$ probability. Average body weights were $* * 0.057, * * * 1.362$, and **** $0.873 \mathrm{~g}$. 
Table 2 Relative insecticidal activities of Dowco -214 and some household insecticides for cockroaches compared with that of fenitrothion

\begin{tabular}{|c|c|c|c|c|c|c|}
\hline \multirow{2}{*}{ Chemical } & \multicolumn{2}{|c|}{$B$. germanica } & \multicolumn{2}{|c|}{ P. americana } & \multicolumn{2}{|c|}{ P. fuliginosa } \\
\hline & $\mathrm{LD}_{50}$ & $\mathrm{LD}_{90}$ & $\mathrm{LD}_{50}$ & $\mathrm{LD}_{90}$ & $\mathrm{LD}_{50}$ & $\mathrm{LD}_{90}$ \\
\hline Dowco-214 & 1.339 & 1. 217 & 1.363 & 1.856 & 0.774 & 0.836 \\
\hline Dursban & 0.756 & 0.799 & 1.449 & 3.591 & 1.135 & 1.419 \\
\hline Fenitrothion & 1.000 & 1.000 & 1.000 & 1.000 & 1.000 & 1.000 \\
\hline Diazinon & 0.695 & 0.647 & 0.606 & 1.591 & 0.889 & 0.643 \\
\hline Malathion & 0.508 & 0.365 & - & - & - & - \\
\hline Fenthion & 0.745 & 0.595 & 0.311 & 0.322 & - & - \\
\hline Dichlorvos & 2.050 & 0.711 & 3.491 & 5.856 & - & - \\
\hline Dieldrin & 0.613 & 0.563 & - & - & - & - \\
\hline
\end{tabular}

リ10頭を放ち，網ぶたをして 4 時閒接触させた後，直径 $9 \mathrm{~cm}$, 高さ $7 \mathrm{~cm}$ のガラス容器に移し餌を与えて, 24 時 間後にそれぞれの生死を観察した。この方法で $25 \pm 1^{\circ} \mathrm{C}$ の室内に保存した合板，およびガラス板の上に残留する 薬剤の効力を所定日数経過ごとに試験したた。

3）継絖時閒接触法による残效性

$10 \times 10 \mathrm{~cm}$ の合板に供試薬剤の $2.5 \%$ 濃度アセトン溶 液 $1 \mathrm{ml}$ を均一に滴下し, 風乾後その上に直径 $9 \mathrm{~cm}$, 高 さ $7 \mathrm{~cm}$ のガラス容器をふせ，その中にチャバネゴキブ リ10頭を放ち，経時的に仰転虫数を観察する方法で $25 \pm$ $1^{\circ} \mathrm{C}$ の室内に放置した合板上に残留する薬剂の效力老所 定日数経過ごとに試験した。

試験はすべて $25 \pm 1{ }^{\circ} \mathrm{C}$ 室内で 3 回くり返し行なっ た。

\section{試験結果および考察}

\section{1. 微量滴下法による殺虫効力}

Dowco-214，および比較に用いた薬剤のチャバネゴニ ブリ，ワモンゴキブリならびにクロゴキブリの雄成虫に 対する幑量㵜下法による殺虫効力試験の結果を表 1 に示 した。これらの結果に見られるよらにチャバネゴキブリ に対する LD50 值は dichlorvos, Dowco-214, fenitrothion, Dursban, fenthion, diazinon, dieldrin および malathion の順に大きくなり，Dowco-214 は高い効力 を示すことがわかった． LD90 では Dowco-214 が最も 高い効力を示した。ワモンジキブリに詨しては dichlorvos, Dursban についで Dowco-214 が高い殺虫効力 を示した。クロゴキブリに対しては，比較薬剤よりも Dowco-214の殺虫效力が少っていたが表 2 に示した fenitrothion との相対力価から考察して Dowco-214 と diazinon の效力に差はなく，むしろ LD90 ではDowco214 が diazinon にまさる結果であった.
Table 3 Knockdown times of male adults of German cockroach for topically applied Dowco-214, Dursban and fenitrothion

\begin{tabular}{l|r|r}
\hline \multicolumn{1}{c|}{ Chemical } & $\begin{array}{c}\text { KT-50 } \\
(\min )\end{array}$ & \multicolumn{1}{|c}{$\begin{array}{c}\text { KT-90 } \\
(\min )\end{array}$} \\
\hline Dowco-214 & 49.20 & 67.92 \\
Dursban & 130.62 & 157.04 \\
Fenitrothion & 79.43 & 102.33 \\
\hline
\end{tabular}

Table 4 Insecticidal activity of Dowco-214 and several household insecticides against female adults of German cockroach evaluated by topical application

\begin{tabular}{|c|c|c|}
\hline Chemical & $\begin{array}{c}\text { Regression } \\
\text { equation }\end{array}$ & $\begin{array}{c}\mathrm{LD}_{50} \\
(\mu \mathrm{g} / \text { 古 })\end{array}$ \\
\hline Dowco-214 & $y=7.181+5.094 x$ & $\begin{array}{c}0.373 \\
(0.308-0.481)\end{array}$ \\
\hline Fenitrothion & $y=8.220+6.943 x$ & $\begin{array}{c}0.352 \\
(0.295-0.405)\end{array}$ \\
\hline Dursban & $y^{\prime}=5.594+3.225 x$ & $\begin{array}{c}0.654 \\
(0.423-0.926)\end{array}$ \\
\hline Malathion & $y=5.280+1.740 x$ & $\begin{array}{c}0.691 \\
(0.264-1.120)\end{array}$ \\
\hline
\end{tabular}

以上の試験の過程で，Dowco-214 を処理したチャバ ネゴキブリがすみやかに仰転することを観察したので， fenitrothion と Dursban を比較薬剂として，1頭をた り $5 \mu \mathrm{g}$ の薬量を処理し，経時的に仰転虫数率を調べた. その結果は表 3 のとおりで, Dowco-214 が fenitrothion の1.63售，Dursban に対しては2.65倍速いKT-50を示 した.この結果は Dowco-214 が比較薬剤に比し，チャ バネゴキブリの作用点に速く到達することを示唆するも のと考えられる。

チャバネゴキブリ雌成虫に対する $\mathrm{LD}_{50}$ は表 4 のとお 
Table 5 Residual effectiveness of several household insecticides on plywood panel or glass plate shown by mortality of male adults of German cockroach exposed at different intervals after the preparation of insecficide residue films

\begin{tabular}{|c|c|c|c|c|c|c|c|c|}
\hline \multirow{2}{*}{$\begin{array}{l}\text { Treated } \\
\text { on }\end{array}$} & \multirow{2}{*}{ Chemical } & \multirow{2}{*}{$\begin{array}{c}\text { Dosage } \\
\left(\mathrm{mg} / 100 \mathrm{~cm}^{2}\right)\end{array}$} & \multicolumn{6}{|c|}{$\begin{array}{c}\text { Mortality }(\%) \\
\text { Days after treatment* }\end{array}$} \\
\hline & & & 0 & 2 & 4 & 8 & 16 & 27 \\
\hline \multirow{8}{*}{ Plywood panel } & Dowco-214 & $\begin{array}{l}0.5 \\
0.125 \\
0.03125\end{array}$ & $\begin{array}{r}100 \\
60.0 \\
0.0\end{array}$ & $\begin{array}{l}100 \\
0.0\end{array}$ & 80.0 & 6.6 & 0.0 & \\
\hline & Dursban & $\begin{array}{l}0.5 \\
0.125 \\
0.03125\end{array}$ & $\begin{array}{r}40.0 \\
10.0 \\
0.0\end{array}$ & $\begin{array}{r}10.0 \\
0.0\end{array}$ & 0.0 & & & \\
\hline & Fenitrothion & $\begin{array}{l}2 \\
0.5 \\
0.125\end{array}$ & $\begin{array}{r}100 \\
30.0 \\
0.0\end{array}$ & $\begin{array}{l}100 \\
0.0\end{array}$ & 73.3 & 13.3 & 0.0 & \\
\hline & Diazion & $\begin{array}{l}2 \\
0.5 \\
0.125\end{array}$ & $\begin{array}{l}100 \\
20.0 \\
10.0\end{array}$ & $\begin{array}{r}100 \\
0.0 \\
0.0\end{array}$ & 46.7 & 0.0 & & \\
\hline & Fenthion & $\begin{array}{l}0.5 \\
0.125 \\
0.03125\end{array}$ & $\begin{array}{r}10.0 \\
10.0 \\
0.0\end{array}$ & $\begin{array}{l}0.0 \\
0.0\end{array}$ & & & & \\
\hline & Dichlorvos & $\begin{array}{l}0.5 \\
0.125 \\
0.03125 \\
0.00781\end{array}$ & $\begin{array}{r}10.0 \\
10.0 \\
0.0 \\
0.0\end{array}$ & $\begin{array}{l}0.0 \\
0.0\end{array}$ & & & & \\
\hline & Dieldrin & $\begin{array}{l}2 \\
0.5 \\
0.125\end{array}$ & $\begin{array}{l}100 \\
100 \\
20.0\end{array}$ & $\begin{array}{r}60.0 \\
0.0 \\
0.0\end{array}$ & 26.0 & 0.0 & & \\
\hline & Trichlorfon & $\begin{array}{l}2 \\
0.5 \\
0.125\end{array}$ & $\begin{array}{r}30.0 \\
30.0 \\
0.0\end{array}$ & $\begin{array}{l}0.0 \\
0.0\end{array}$ & & & & \\
\hline \multirow{8}{*}{ Glass plate } & Dowco-214 & $\begin{array}{l}0.5 \\
0.125 \\
0.03125\end{array}$ & $\begin{array}{l}100 \\
100 \\
80.0\end{array}$ & $\begin{array}{l}100 \\
10.0 \\
0.0\end{array}$ & $\begin{array}{r}46.7 \\
0.0\end{array}$ & 0.0 & & \\
\hline & Dursban & $\begin{array}{l}0.5 \\
0.125 \\
0.03125\end{array}$ & $\begin{array}{l}100 \\
100 \\
20.0\end{array}$ & $\begin{array}{l}100 \\
80.0 \\
10.0\end{array}$ & $\begin{array}{r}80.0 \\
46.7 \\
0.0\end{array}$ & $\begin{array}{l}6.7 \\
6.7\end{array}$ & $\begin{array}{l}0.0 \\
0.0\end{array}$ & \\
\hline & Fenitrothion & $\begin{array}{l}2 \\
0.5 \\
0.125\end{array}$ & $\begin{array}{l}100 \\
100 \\
90.0\end{array}$ & $\begin{array}{l}100 \\
100 \\
20.0\end{array}$ & $\begin{array}{r}100 \\
93.3 \\
0.0\end{array}$ & $\begin{array}{r}66.7 \\
6.7\end{array}$ & $\begin{array}{l}0.0 \\
0.0\end{array}$ & \\
\hline & Diazinon & $\begin{array}{l}2 \\
0.5 \\
0.125\end{array}$ & $\begin{array}{l}100 \\
100 \\
100\end{array}$ & $\begin{array}{c}100 \\
70.0 \\
0.0\end{array}$ & $\begin{array}{l}40.0 \\
26.7\end{array}$ & $\begin{array}{l}6.7 \\
0.0\end{array}$ & 0.0 & \\
\hline & Fenthion & $\begin{array}{l}0.5 \\
0.125 \\
0.03125\end{array}$ & $\begin{array}{l}100 \\
70.0 \\
0.0\end{array}$ & $\begin{array}{l}80.0 \\
20.0\end{array}$ & $\begin{array}{r}80.0 \\
0.0\end{array}$ & 13.3 & 0.0 & \multirow{4}{*}{0.0} \\
\hline & Dichlorvos & $\begin{array}{l}0.5 \\
0.125 \\
0.03125 \\
0.00781\end{array}$ & $\begin{array}{l}0.0 \\
0.0 \\
0.0 \\
0.0\end{array}$ & & & & & \\
\hline & Dieldrin & $\begin{array}{l}2 \\
0.5 \\
0.125\end{array}$ & $\begin{array}{l}100 \\
100 \\
50.0\end{array}$ & $\begin{array}{l}100 \\
100 \\
0.0\end{array}$ & $\begin{array}{l}93.3 \\
60.0\end{array}$ & $\begin{array}{l}66.7 \\
20.0\end{array}$ & $\begin{array}{r}50.0 \\
0.0\end{array}$ & \\
\hline & Trichlorfon & $\begin{array}{l}2 \\
0.5 \\
0.125\end{array}$ & $\begin{array}{l}90.0 \\
40.0 \\
10.0\end{array}$ & $\begin{array}{l}0.0 \\
0.0 \\
0.0\end{array}$ & & & & \\
\hline
\end{tabular}

* Days elapsed after the insecticide films were prepared. 
Table 6 Residual effectiveness of several household insecticides on plywood panel evaluated by knockdown time of German cockroach

\begin{tabular}{|c|c|c|c|c|c|c|c|c|c|c|c|}
\hline \multirow{2}{*}{ Sex } & \multirow{2}{*}{ Chemical } & \multirow{2}{*}{$\begin{array}{l}\text { Level of } \\
\text { activity } \\
\text { (min) }\end{array}$} & \multicolumn{9}{|c|}{ Days* } \\
\hline & & & 0 & 7 & 14 & 21 & 28 & 35 & 49 & 63 & 85 \\
\hline \multirow{4}{*}{ Male } & Dowco-214 & $\begin{array}{l}\mathrm{K} \mathrm{T}-50 \\
\mathrm{~K} \mathrm{~T}-90\end{array}$ & $\begin{array}{l}64 \\
92\end{array}$ & $\begin{array}{l}73 \\
97\end{array}$ & $\begin{array}{r}83 \\
130\end{array}$ & $\begin{array}{l}156 \\
219\end{array}$ & $\begin{array}{l}108 \\
178\end{array}$ & $\begin{array}{l}155 \\
215\end{array}$ & $\begin{array}{l}185 \\
225\end{array}$ & $\begin{array}{l}209 \\
310\end{array}$ & \\
\hline & Dursban & $\begin{array}{l}\mathrm{K} T-50 \\
\mathrm{~K} T-90\end{array}$ & $\begin{array}{r}99 \\
122\end{array}$ & $\begin{array}{l}170 \\
220\end{array}$ & $\begin{array}{l}251 \\
309\end{array}$ & $\begin{array}{l}224 \\
293\end{array}$ & $\begin{array}{l}255 \\
309\end{array}$ & $\begin{array}{l}295 \\
394\end{array}$ & $\begin{array}{l}188 \\
303\end{array}$ & $\begin{array}{l}252 \\
405\end{array}$ & \\
\hline & Fenitrothion & $\begin{array}{l}\mathrm{K} T-50 \\
\mathrm{~K} T--90\end{array}$ & $\begin{array}{l}106 \\
127\end{array}$ & $\begin{array}{l}161 \\
181\end{array}$ & $\begin{array}{l}136 \\
172\end{array}$ & $\begin{array}{l}150 \\
175\end{array}$ & $\begin{array}{l}133 \\
172\end{array}$ & $\begin{array}{l}151 \\
180\end{array}$ & $\begin{array}{l}146 \\
171\end{array}$ & $\begin{array}{l}169 \\
204\end{array}$ & \\
\hline & Diazinon & $\begin{array}{l}\mathrm{K} \mathrm{T}-50 \\
\mathrm{~K} \mathrm{~T}-90\end{array}$ & $\begin{array}{l}73 \\
92\end{array}$ & $\begin{array}{l}132 \\
175\end{array}$ & $\begin{array}{l}145 \\
162\end{array}$ & $\begin{array}{l}274 \\
447\end{array}$ & $\begin{array}{l}302 \\
372\end{array}$ & $\begin{array}{l}337 \\
458\end{array}$ & $\begin{array}{l}261 \\
318\end{array}$ & $\begin{array}{l}356 \\
436\end{array}$ & \\
\hline \multirow{4}{*}{ Female } & Dowco-214 & $\begin{array}{l}\mathrm{K} T-50 \\
\mathrm{~K} T-90\end{array}$ & $\begin{array}{l}149 \\
178\end{array}$ & $\begin{array}{l}115 \\
174\end{array}$ & $\begin{array}{l}104 \\
141\end{array}$ & $\begin{array}{l}151 \\
219\end{array}$ & $\begin{array}{l}122 \\
153\end{array}$ & $\begin{array}{l}176 \\
324\end{array}$ & $\begin{array}{l}184 \\
229\end{array}$ & $\begin{array}{l}215 \\
288\end{array}$ & $\begin{array}{l}318 \\
413\end{array}$ \\
\hline & Dursban & $\begin{array}{l}\mathrm{K} T-50 \\
\mathrm{~K} T-90\end{array}$ & $\begin{array}{l}222 \\
252\end{array}$ & $\begin{array}{l}182 \\
223\end{array}$ & $\begin{array}{l}209 \\
269\end{array}$ & $\begin{array}{l}216 \\
355\end{array}$ & $\begin{array}{l}240 \\
355\end{array}$ & $\begin{array}{l}257 \\
449\end{array}$ & $\begin{array}{l}187 \\
278\end{array}$ & $\begin{array}{l}211 \\
291\end{array}$ & $\begin{array}{l}341 \\
403\end{array}$ \\
\hline & Fenitrothion & $\begin{array}{l}\mathrm{K} T-50 \\
\mathrm{~K} T-90\end{array}$ & $\begin{array}{l}162 \\
197\end{array}$ & $\begin{array}{l}129 \\
170\end{array}$ & $\begin{array}{r}98 \\
122\end{array}$ & $\begin{array}{l}110 \\
140\end{array}$ & $\begin{array}{l}106 \\
155\end{array}$ & $\begin{array}{l}131 \\
182\end{array}$ & $\begin{array}{l}163 \\
197\end{array}$ & $\begin{array}{l}260 \\
398\end{array}$ & $\begin{array}{l}206 \\
273\end{array}$ \\
\hline & Diazinon & $\begin{array}{l}\mathrm{K} \mathrm{T}-50 \\
\mathrm{~K} \mathrm{~T}-90\end{array}$ & $\begin{array}{l}152 \\
181\end{array}$ & $\begin{array}{l}112 \\
135\end{array}$ & $\begin{array}{l}152 \\
195\end{array}$ & $\begin{array}{l}224 \\
331\end{array}$ & $\begin{array}{l}160 \\
245\end{array}$ & $\begin{array}{l}207 \\
313\end{array}$ & $\begin{array}{l}168 \\
209\end{array}$ & $\begin{array}{l}197 \\
262\end{array}$ & $\begin{array}{l}385 \\
631\end{array}$ \\
\hline
\end{tabular}

* Days elapsed after the insecticide residue paneles were prepared.

Plywood panels were treated with a dosage of $25 \mathrm{mg} / 100 \mathrm{~cm}^{2}$.

りで，篧より薬剤感受性が低い傾向を示した。鈴木ら (1962)は，薬剤感受性系統のチャバネゴキブリに対する 処理24時間後の $\mathrm{LD}_{50}(\mu \mathrm{g} /$ 早)が diazinon 0.39 , malathion 0.48 , dichlorvos 0.15 , fenthion 0.33 , fenitrothion 0.25 , dieldrin 0.33 であったと報告しているが, これらの数値は表 4 の結果と比較的よく一致している. 本試験に供試したチャバネゴキブリは薬剤感受性系統と 考えられる。

\section{2. 限定時間接触法による残効性}

本試験は，種々の濃度に稀釈した Dowco-214 および 比較薬剤のガラス板，合板上に残留する効力を知る目的 で行なった。

試駼結果は表 5 に示すと抢りで，ガラス板処理薬量 $0.5 \mathrm{mg} / 100 \mathrm{~cm}^{2}$ でチャバネゴキブリ雄成虫を $100 \%$ 死亡 させうる薬咸は，Dowco-214，fenitrothion, Dursban, dieldrin, fenthion および diazinon であったが， trichlorfon は 40\%を死亡させる 殺虫力しか示さず， dichlorvos にはまったく殺虫効力が認められなかった，処理 8 日後では, dieldrin, Dursban, fenitrothion および fenthion が死亡率 $20 \%$ 以下に低下し，Dowco-214，diazinon は殺虫力を示さなかった。 さらに処理 16 日後で

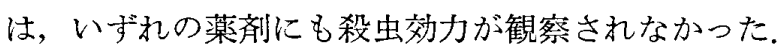

一方合板処理薬量 $0.5 \mathrm{mg} / 100 \mathrm{~cm}^{2}$ では, fenitrothion についで Dowco-214 の残効が長く，比較薬剤と明らか な差がみられた。井上 (1956), Mathis and Schoof
（1963）が，薬剤の残效性は処理面によって左右されると 同時に, 同一処理面でも薬凨の種類や骺型によって異な ることを報告している．本試験においても処理面の相違 によって，処理直後の殺䗋力打よび残効性に大きな差 がみられた。すなわち，ガラス板のような平滑で非吸収 性の面では，チャバネゴキブリとの接触する絶対薬量も 多く, 処理直後の殺虫効力および残効性も大きいが，合 板など吸収性の大きい面では絶刘薬量の減少により, 殺 虫効力が急激汇低下した。 Dichlorvos のように, 微量 滴下法による殺虫効力が高いのにもかかわらず，ガラス 板処理に扔いて効力が低い理由は，処理法の相違，およ び蒸気圧 $\left(1.5 \times 10^{-1} \mathrm{mmHg}\right.$ : 武藤, 1970) が大きく, 比 較的早く揮散するためと推察される。 また Dowco-214 が合板処理で，比較的長い残効性を示寸理由は，イエバ エに対する Vapour action が Dursban, diazinon, dieldrin, fenitrothion, fenthion 㧍よび malathion に 比較して高い（Kitagaki et al., 1972）ことから推察し て，处理合板から徐々に揮散して殺虫効力老あらわすも の上考えられる。

\section{3． 継続時間接触法による残効性}

ゴキブリ駆除法の1つとして殺虫剤の局所重点残留塗 布法があり, 井上 (1958), 白井ら (1959), 抢よび鈴木 ら（1959）の多くの研究がある.

本試験は Dowco-214 の残留塗布による実用性を検討 する目的で行なった。 その結果は表 6 亿示すとおり，チ 
ヤバネゴキブリ雄成虫に対する Dowco-214 の效力は処 理28日後まで fenitrothion, Dursban, diazinon にまさ り，63日後では fenitrothion にやや劣るが Dursban, diazinon よりすぐれた効力を示した，Fenitrothion で は処理直後の効力が Dowco-214 に比べて低いが，比較 的安定した残效性を示した。 Dursban， diazinon は処理 14 日後で，処理直後の効力に比較し約 $1 / 2$ の効力低下がみ られた。

一方，雌成虫についても同様の傾向が観察されたが， 薬蝺に対する感受性は雄成虫に比較し低い結果であっ た.

以上の試験結果から，Dowco-214 は局所重点残留塗 布によって比較的長い残効性を示し，実用性が十分期待 できると考えられる。

\section{要 約}

低㨞性有機燐殺虫剂 Dowco-214 のゴキブリ類に対す る殺虫効力を局所施用，および接触法によって評価した 結果は,つぎのように要約される.

1. 微量滴下法によるチャバネゴキブリ雄成虫に対す る効力は，LD50 では dichlorvos についで Dowco-214 が高くLDs0 では Dowco-214 が最も高い効力を示した. また Dowco-214 はワモンゴキブリ雄成虫に対して dichlorvos, Dursban についで高い効力を示し，クロゴキブ リ雄成虫に対し，Dowco-214 は Dursban に少るが, diazinon と有意な差はなく， $\mathrm{LD}_{90}$ では diazinon にま さる効力であった。

2. 陲定時間接触法によるガラス板，および合板上の 残効性は,前者では比較的短いが,後者では fenitrothion についで長期間殺虫力を示した.

3. 継続時間接触法による合板上での残効性の場合, Dowco-214 は fenitrothion と同程度であり，Dursban， diazinonよりすぐれていた.

以上の試験結果から，Dowco-214 はゴキブリ類に対 しすぐれた殺虫効力，および残效性を有し実用性は期待 できると考えられる。

\section{引用文献}

井上博之, 安閒勝男, 北垣忠温, 小島建一 (1971): Dowco-214の環境毒物学的評価. 日本昆虫学会, 日 本応用動物昆虫学会東海支部合同例会講演（1971 年 11月23日，菊川）

井上義郷 (1956)：防疫用殺虫剂の残効性に関する研究 (第 1 報)，殺虫剂残渣の持続性と撒布面との関係. 衛生動物，7(1) : 43-50.

井上義郷 (1958)：防疫用殺虫剂の残効性に関する研究 (第IV報)，ゴキブリに対する殺虫剤の局所重点残留
塗布と効果の変動. 衛生動物, 9(4)：289-293.

Kenaga, E. E., W. K. Whitney, J. L. Hardy and A. E. Doty (1965) : Laboratory tests with Dursban insecticide. J. Econ. Entomol., 58(6) : 10431050.

Kenaga, E. E. (1971) : Some physical, chemical, and insecticidal properties of some O,O-dialkyl O- (3, 5, 6-trichloro-2-pyridyl) phosphates and phosphorothioate. Bull. Wld Hlth Org., 44 : 225228.

Kitagaki, T., I. Nakayama, S. Sugiyama and T. Otokozawa (1972) : Effectiveness of Dowco-214 on some insects of public health importance(II). Laboratory evaluation tests of the insecticidal activity for the common house fly. Jap. J. Sanit. Zool. (in press).

Mathis, W. and H. F. Schoof (1963) : The effect of surface material, retreatment and formulation on the residual activity of several insecticides. Mosquit News, 23(2) : 140-149.

武藤聡雄 (1970)：農薬概説， pp. 728-731，技報堂， 東京.

Nakayama, I., T. Kuroda, T. Kitagaki and H. Shinohara (1972) : Bagworms: The effectiveness of several insectivide formulation against the larvae of three species. J. Econ. Entomol., (In press).

中山 勇, 北垣忠温, 黒田達夫 (1971) : Dowco-214の アブラムシ類に対する殺虫効果. 日本昆虫学会. 日 本応用動物昆虫学会東海支部合同例会講演（1971年 11月23日，菊川).

Rigterink, R. H. and E. E. Kenaga (1966) : Synthesis and insecticidal activity of some O, O-dialkyltrichloro-2-pyridyl phosphates and phosphorothioates, J. Agr. Food Chem., 14(13) : 304-306.

白井允子, 平社俊之助, 鈴木 猛 (1959)：数種殺虫剤 残渣のチャバネゴキブリ成虫に対する累積接触効果 について。衛生動物, $10(4): 280-283$.

鈴木 猛, 平社俊之助, 传藤金作 (1959) : 某病院内に おけるチヤバネゴキブリ Blattella germanica L. のダイアジノンによる駆除の 1 例. 衛生動物, 10 (1): 78-79.

鈴木 猛, 松永秀子, 白井允子 (1962)：各種有機燐剤 のチャバネゴキブリに対する殺虫効力比較. 衛生動 物, $13(2): 116-112$.

\section{Summary}

Insecticidal activities of Dowco-214, $O, O$-di methyl $O$-(3,5, 6-trichloro-2-pyridyl) phosphorothioate, against the German cockroach, Blattella germanica L., the American cockroach, Periplaneta americana L., and the smoky brown cockroach, Periplaneta fuliginosa L., were evaluated under a laboratory condition of $25 \pm 1^{\circ} \mathrm{C}$ and $60 \pm$ $5 \%$ R.H. 
The $\mathrm{LD}_{50}$ 's for male adults of the German cockroach determined by topical application decreased in order of dichlorvos, Dowco-214, fenitrothion, Dursban, fenthion, diazinon, dieldrin and malathion. At the level of $\mathrm{LD}_{90}$, Dowco-214 was most effective.

For male adults of the American cockroach, the LD 50 's decreased in order of dichlorvos, Dursban, Dowco-214, fenitrothion, diazinon and fenthion.

In the test using male adults of the smoky brown cockroach, Dursban was most effective and the LD50's decreased in order of fenitrothion, diazinon and Dowco-214. However, the differ- ences of toxicities between Dowco-214, fenthion and fenitrothion were not significant.

Residual effectiveness of Dowco-214 on plywood panel tested by the limited time contact method was longer than that of several insecticides. In the test by the succesive time contact method, effective persistence of Dowco-214 on plywood panel was longer than that of Dursban and diazinon.

It is presumed that Dowco-214 is one of the most promising insecticides for controlling insects of public health importance because of its higher insecticidal activity, longer residual effectiveness and lower toxicity to mammals. 